\title{
Mediastinal and Subcutaneous Chest Fat Are Differentially Associated with Emphysema Progression and Clinical Outcomes in Smokers
}

\author{
Jon Grace ${ }^{a}$ Joseph K. Leader ${ }^{b}$ Seyed M. Nouraie ${ }^{c}$ Jiantao Pu ${ }^{b}$ \\ Divay Chandra ${ }^{c}$ Yingze Zhang ${ }^{c}$ Frank C. Sciurba ${ }^{c}$ Jessica Bon ${ }^{c}$ \\ Departments of a General Internal Medicine and ${ }^{b}$ Radiology, and ${ }^{c}$ Division of Pulmonary, Allergy, and Critical Care \\ Medicine, University of Pittsburgh Medical Center, Pittsburgh, PA, USA
}

\section{Keywords}

Pulmonary disease $\cdot$ Interleukin-6 $\cdot$ C-reactive protein .

Body composition - Computed tomography

\begin{abstract}
Background: Studies have demonstrated both positive and negative effects of obesity on clinical outcomes in chronic obstructive pulmonary disease (COPD). In other chronic diseases, fat location is differentially associated with disease outcomes; however, this relationship has not been well studied in COPD. Objective: To determine if fat location explains the differential association of body mass index (BMI) with clinical outcome measures in smokers. Methods: Baseline and 6-year chest computed tomography scans from 68 current and former smokers were used to quantify mediastinal and subcutaneous fat. The relationships of BMI, mediastinal fat, and subcutaneous fat with cross-sectional and 6-year changes in pulmonary function, incremental shuttle walk distance (ISWD), quantitative emphysema, and circulating interleukin-6 (IL-6) and C-reactive protein (CRP) levels were assessed using generalized linear models adjusted for clinically relevant covariates. Results: Baseline subcutaneous fat was negatively associated with emphysema progression
\end{abstract}

\section{KARGER}

() 2017 S. Karger AG, Basel

E-Mail karger@karger.com

www.karger.com/res
For editorial comment see p. 488

over 6 years $(p<0.01)$. BMI and mediastinal fat volume were inversely associated with baseline ISWD ( $p<0.01$ and $p=$ 0.043 , respectively) as well as 6-year change in ISWD ( $p=$ 0.020 and $p=0.028$, respectively). IL-6 was directly associated with BMI and mediastinal fat $(p<0.01)$ and CRP was directly associated with BMI only $(p=0.033)$. Conclusions: Increased subcutaneous chest fat is associated with less emphysema progression over time in smokers, while increased mediastinal fat volume is associated with decreased walk distance and increased IL- 6 levels. These findings suggest a complex interaction between fat, inflammation, and emphysema that should be considered when phenotyping patients with COPD and provide new evidence of an inverse association between emphysema progression and chest subcutaneous fat.

(c) 2017 S. Karger AG, Basel

\section{Introduction}

Chronic obstructive pulmonary disease (COPD) is projected to become the fifth most common disease and the fourth leading cause of death worldwide by 2020 [1]. Systemic manifestations, such as body composition ab- 
normalities, significantly contribute to disease morbidity and mortality in COPD. While a low body mass index (BMI) is a well-accepted marker of poor outcomes [2], an understanding of the impact of obesity on COPD is complicated by the presence of conflicting data. In COPD patients, obesity has been associated with insulin resistance, increased cardiovascular mortality, and decreased measures of lung function as measured by forced vital capacity $(\mathrm{FVC})$ and forced expiratory volume in $1 \mathrm{~s}\left(\mathrm{FEV}_{1}\right)$ [3]. Yet, a high BMI was also associated with less emphysema [4] and improved survival when compared to normal and lower BMI in previous studies [5].

The complex relationship between obesity and COPD suggests that not only the quantity but also the location and metabolic profile of fat may be related to COPD outcomes. In other chronic diseases, including cardiovascular disease [6], liver disease [7, 8], and osteoporosis [9], mediastinal and visceral fat have been associated with negative outcomes, whereas subcutaneous fat has demonstrated protective effects. Abdominal and chest computed tomography (CT) imaging obtained for research purposes has been used previously to quantify and separate fat into visceral, mediastinal, and subcutaneous compartments $[10,11]$. With the increasing clinical use of chest CT imaging for lung cancer screening in the United States, there is an opportunity to gain insight into fat distribution in a larger population and how it is associated with clinical outcomes in COPD. We investigated the association of subcutaneous and mediastinal fat with measures of lung function, exercise capacity, quantitative emphysema, and circulating biomarkers in a cohort of current and former smokers at baseline and 6-year follow-up. We hypothesized that mediastinal and subcutaneous fat would be differentially associated with these measures and potentially explain conflicting reports regarding the impact of adiposity on COPD.

\section{Methods}

\section{Study Sample}

A subset of 68 subjects was randomly selected from the 201 participants in the University of Pittsburgh Specialized Centers for Clinically Oriented Research (SCCOR) cohort based on power calculations showing greater than $80 \%$ power to detect a moderate effect (correlation coefficient 0.35-0.49) with this sample size. All cohort participants with completed baseline and 6-year chest CT data were eligible for selection. Details of this cohort have been described previously [12]. Briefly, cohort participants were current or former smokers aged 40 years or older with a minimum of 10 pack-years tobacco history at enrollment. Exclusion criteria included chronic daily prednisone use, clinical or radiographic evi- dence of another significant pulmonary diagnosis (e.g., interstitial lung disease), history of lung cancer or a new, suspicious nodule on CT scan, and obesity with a BMI $>34$. The study protocol was approved by the University of Pittsburgh Institutional Review Board, and written informed consent was obtained for each participant.

\section{CT Analysis}

Noncontrast chest CT examinations were performed with a General Electric (GE) LightSpeed VCT (64-detector) scanner. Emphysema was visually scored using a previously validated 6-point semiquantitative system [13]. The percentage of low-attenuation areas (LAA\%) was defined as the percentage of lung voxels with computed attenuation values less than -950 Hounsfield units (HU) after applying a three-dimensional median filter based on the traditional density mask approach [14].

CT images used to evaluate body composition were reconstructed at $2.5 \mathrm{~mm}$ thickness using GE's "standard" kernel. The regions of interest on CT images depicting mediastinal and subcutaneous fat were manually outlined image-by-image by one of the study authors (J.G.) using proprietary software. The mediastinal compartment was defined by the CT image containing the aortic arch split superiorly, the CT image where the heart border first touched the diaphragm inferiorly, the sternum anteriorly, the most anterior portion of the vertebral bodies posteriorly, and the pericardium/mediastinal fat laterally (Fig. 1). These borders were adapted from a previous study on thoracic and epicardial fat [11]. The subcutaneous compartment was defined by all tissue superficial to the most superficial muscles (Fig. 1). Mediastinal and subcutaneous fat were quantified as the volume of segmented tissue voxels with a value between -190 and $-30 \mathrm{HU}$ [15]. Manual quantification of thoracic fat on CT images has previously been shown to be highly reproducible [16], and the CT imaging modality is considered the gold standard for quantifying fat by location. A subjective measure of subcutaneous fat tissue outside the CT field of view (none/minimal/moderate/excessive) was collected at the time of reviewing CT images as well.

\section{Statistical Analysis}

The relationship between baseline and 6-year change in BMI, subcutaneous fat, and mediastinal fat was assessed with Pearson correlation. The association of baseline and 6-year change in BMI, subcutaneous fat, and mediastinal fat (independent variables) with baseline (cross-sectional) and 6-year change in $\mathrm{FEV}_{1}, \mathrm{FEV}_{1} / \mathrm{FVC}$, incremental shuttle walk distance (ISWD), and LAA\% (primary outcome variables) was assessed using individual multivariate robust linear regression modeling to obtain standardized beta coefficients. Standardized beta coefficients convert data to $Z$ scores and allow for coefficients to be compared across different independent variables for effect on variation of the dependent variable [17]. Individual models were selected instead of a combined model given the high degree of correlation seen between the fat measures on Pearson correlation.

Each model was adjusted for factors known to be associated with the outcome variable of interest. The association with $\mathrm{FEV}_{1}$ and $\mathrm{FEV}_{1} / \mathrm{FVC}$ was adjusted for age, gender, pack-years, and active smoking status [18]. The association with ISWD was adjusted for $\mathrm{FEV}_{1}$, height, age, and gender [19]. Coronary artery calcium scores were considered for ISWD model inclusion but were found to not be significantly associated with either ISWD or fat location 

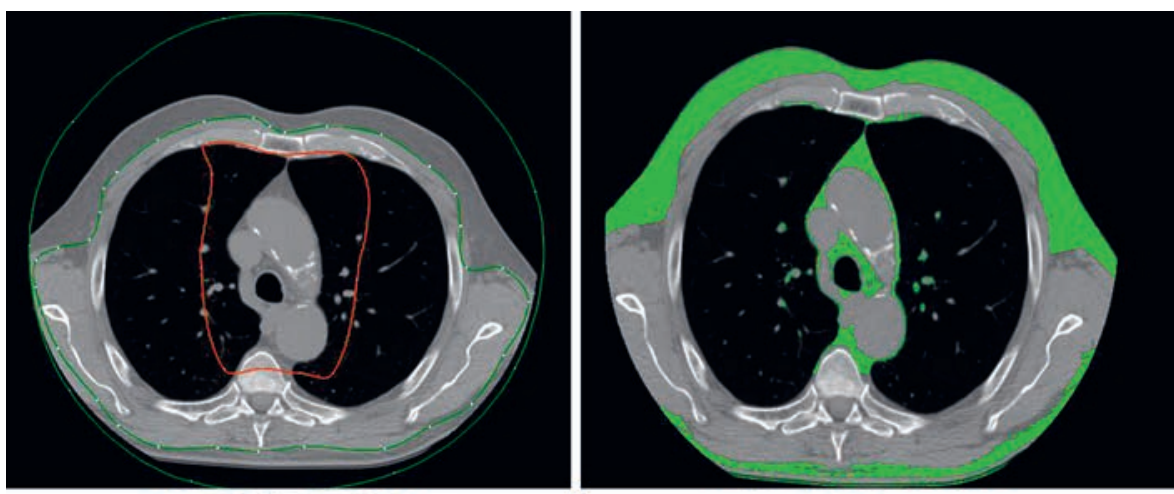

Fig. 1. Examples of the superior (top) and inferior (bottom) borders of the mediastinal compartment with contours applied. The green line represents the subcutaneous contour and the red line the mediastinal contour. Their respective fat measurements are demonstrated next to the images with the -30 to -190 Hounsfield unit masks applied. Images were processed with 6- $\mathrm{mm}$ section thickness between these two borders to generate the fat volumes.
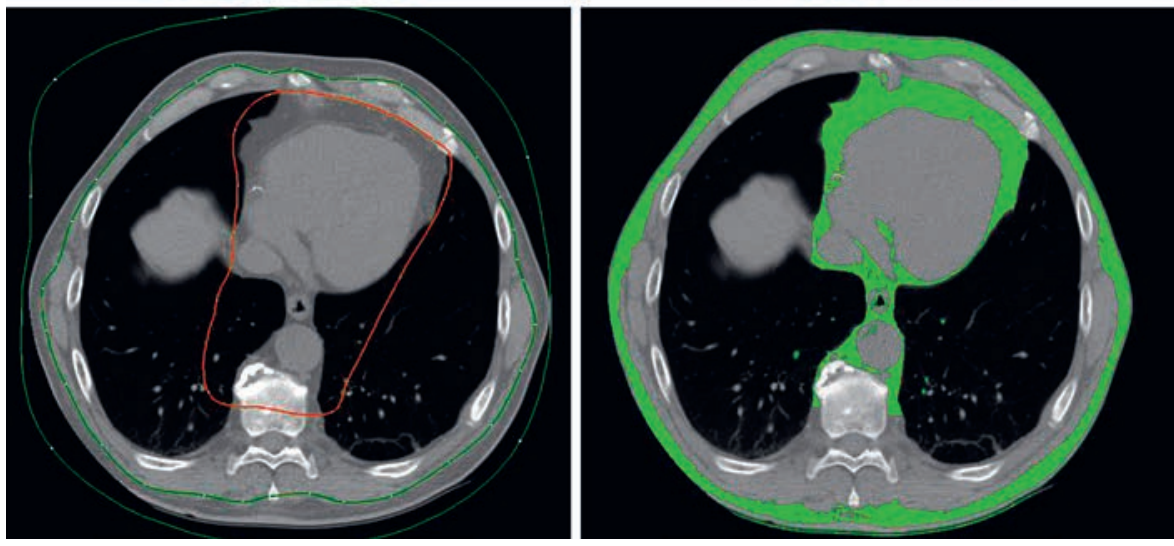

and were excluded to optimize model accuracy for the sample size. The association with LAA\% was adjusted for gender, age, and pack-years [20]. Six-year changes of primary outcome variable models were adjusted for the respective baseline outcome parameter value to account for regression toward the mean [21]. Models that included 6-year change in fat measures were similarly adjusted. Subcutaneous fat 6-year change data was excluded from the analysis due to the variability of the amount of subcutaneous fat captured in the field of view between baseline and 6-year CT scans for obese subjects. The inclusion of an independent variable estimating the amount of subcutaneous fat excluded from the field of view (none/minimal/moderate/excessive) in baseline multivariate models did not change the significance threshold of any of the results and was therefore excluded from the final models.

IL-6 and C-reactive protein (CRP) values were natural logtransformed and their association with baseline BMI, subcutaneous fat, mediastinal fat, and outcomes was assessed by multivariate linear regression modeling with adjustments for age, current smoking status, and appropriate covariates as noted above [22]. Path analysis, a subset of structural equation modeling, is a statistical technique useful for assessing complex interactions between different variables on an outcome [23]. Path analysis was performed for ISWD and emphysema progression utilizing fat measures and inflammatory markers. Standardized coefficients with $p$ values and root mean square error of approximation (RMSEA, a measure of model fitness) were reported for path analyses. All statistical analyses were performed using STATA 13.1 (StataCorp, College Station, TX, USA) and all $p$ values $<0.05$ were considered statistically significant.

Chest Fat Is Differentially Associated with Emphysema

\section{Results}

\section{Subject Characteristics}

The median age of the cohort was 65.5 years with an equal distribution of men and women (Table 1). Participants were predominantly non-Hispanic White. All participants had significant exposure to tobacco and over one-third were actively smoking at the time of study entry. There was a modest prevalence of airflow obstruction amongst the subjects with $39.7 \%$ of the cohort having at least moderate airflow obstruction and $38.2 \%$ presenting without evidence of airflow obstruction. Less than onequarter of the participants reported regular inhaled corticosteroid use and only $13.2 \%$ had any previous acute exacerbation of COPD (Table 1). The prevalence of emphysema was high with $62.7 \%$ having at least trace emphysema by visual assessment on CT scan. The magnitude of 6-year change was modest for most measures with a trend toward disease progression (Table 1).

\section{BMI and Fat Association}

BMI was directly associated with both subcutaneous and mediastinal fat both at baseline $\left(R^{2}=0.47\right.$ and 0.55 , $p<0.01$, respectively) and at the 6 -year follow-up visit 
Table 1. Sample characteristics

\begin{tabular}{|c|c|c|}
\hline & Baseline $(n=68)$ & Six-year change \\
\hline Age, years & $65.5(60,68.5)$ & $5(5,6)(n=66)$ \\
\hline \multicolumn{3}{|l|}{ Gender, $n(\%)$} \\
\hline Female & $34(50.0)$ & \\
\hline Male & $34(50.0)$ & \\
\hline \multicolumn{3}{|l|}{ Ethnicity, $n(\%)$} \\
\hline Caucasian & $63(92.6)$ & \\
\hline Other ${ }^{1}$ & $5(7.4)$ & \\
\hline $\mathrm{FEV}_{1}, \%$ predicted & $85.9(63.3,96.4)$ & $-2.4(-9.6,2.6)(n=65)$ \\
\hline $\mathrm{FEV}_{1} / \mathrm{FVC}$ & $0.68(0.55,0.74)$ & $-0.01(-0.04,0.02)(n=65)$ \\
\hline \multicolumn{3}{|l|}{ GOLD classification, $n(\%)$} \\
\hline At risk & $26(38.2)$ & $24(36.9)$ \\
\hline I (mild) & $15(22.1)$ & $8(12.3)$ \\
\hline II (moderate) & $18(26.5)$ & $21(32.3)$ \\
\hline III/IV (severe) & $9(13.2)$ & $12(18.5)$ \\
\hline LAA\% & $0.9(0.5,4.2)$ & $0.0(-0.2,1.6)(n=67)$ \\
\hline \multicolumn{3}{|l|}{ Visual emphysema score ${ }^{2}, n(\%)$} \\
\hline None & $25(37.3)$ & $22(33.3)$ \\
\hline Trace-mild & $28(41.8)$ & $28(42.4)$ \\
\hline Moderate-severe & $14(20.9)$ & $16(24.3)$ \\
\hline Smoking, pack-years & $58(40,75)$ & $0.00(0,1.5)(n=68)$ \\
\hline Current smoker, $n(\%)$ & $26(38.2)$ & $24(35.8)(n=67)$ \\
\hline Daily ICS use, $n(\%)$ & $14(20.6)$ & $20(29.9)(n=67)$ \\
\hline ISWD, $\mathrm{m}$ & $430(330,540)$ & $-100(-140,-40)(n=45)$ \\
\hline SGRQ score & $21.7(8.6,31.3)$ & $-0.4(-5.4,4.9)(n=65)$ \\
\hline Previous exacerbation experienced, $n(\%)$ & $7(13.2)$ & $12(23.1)(n=52)$ \\
\hline \multicolumn{3}{|l|}{ BMI, $n(\%)$} \\
\hline Normal (18.5-24.9) & $18(26.5)$ & $20(29.4)$ \\
\hline Overweight (25-29.9) & $26(38.2)$ & $25(36.8)$ \\
\hline Obese $(>30)$ & $24(35.3)$ & $23(33.8)$ \\
\hline
\end{tabular}

Unless otherwise noted, values are presented as median (interquartile range). $\mathrm{FEV}_{1}$, forced expiratory volume in $1 \mathrm{~s}$; GOLD, Global Initiative for Chronic Obstructive Lung Disease [44]; LAA\%, low-attenuation area percentage; ICS, inhaled corticosteroid; ISWD, incremental shuttle walk distance; SGRQ, Saint George Respiratory Questionnaire; BMI, body mass index. ${ }^{1}$ "Other" ethnicity included 2 African Americans and 3 multiracial subjects. ${ }^{2}$ One subject did not have a visual emphysema score at baseline.

$\left(R^{2}=0.30\right.$ and $0.41, p=0.016$ and $p<0.01$, respectively). Over 6 years, mean BMI increased 1.2\%, mean subcutaneous fat increased $4.8 \%$, and mean mediastinal fat increased 9.5\%. Change in BMI was directly associated with change in subcutaneous and mediastinal fat $\left(R^{2}=0.43\right.$ and $0.71, p<0.01$, respectively).

\section{Association of Fat Measures with Functional \\ Outcomes and Emphysema}

BMI was significantly associated inversely with ISWD in cross-sectional $(p<0.01)$ and longitudinal $(p=0.020$; Table 2) analysis. Only mediastinal fat shared this relationship with ISWD in both cross-sectional and longitudinal analysis ( $p=0.043$ and 0.028 , respectively; Table 2 ).
The only measure of pulmonary function that was significantly associated with any fat measure was $\mathrm{FEV}_{1} / \mathrm{FVC}$ in cross-section directly with BMI ( $p=0.011$; Table 2$)$. Models that assessed 6-year change in fat measures and outcome variables were significant only for mediastinal fat and $\mathrm{FEV}_{1} / \mathrm{FVC}$ (standardized $\beta=0.32, p=0.027$ ).

In this small subset of the SCCOR cohort, we were unable to replicate our previous findings of an inverse association between BMI and LAA\% [4], although a trend between baseline BMI and baseline and 6-year change in LAA $\%$ existed (standardized $\beta=-0.28$ and $-0.31, p=$ 0.058 and $p=0.054$, respectively; Table 2 ). Subcutaneous, but not mediastinal, fat was significantly associated with 6 -year change in LAA\% $(p<0.01$; Table 2$)$. 
Table 2. Baseline fat measure associations with outcome measures and LAA\%

\begin{tabular}{|c|c|c|c|}
\hline & Mediastinal fat & Subcutaneous fat & BMI \\
\hline \multicolumn{4}{|l|}{$\operatorname{ISWD}(\mathrm{m})^{1}$} \\
\hline Baseline $(n=65)$ & $-0.22(0.043)$ & $-0.10(0.25)$ & $-0.25(<0.01)$ \\
\hline Six-year change $(n=45)$ & $-0.27(0.028)$ & $-0.16(0.19)$ & $-0.27(0.020)$ \\
\hline \multicolumn{4}{|l|}{$\mathrm{FEV}_{1}(\% \text { predicted })^{2}$} \\
\hline Baseline $(n=68)$ & $-0.14(0.27)$ & $0.030(0.81)$ & $0.20(0.13)$ \\
\hline Six-year change $(n=65)$ & $-0.064(0.57)$ & $-0.056(0.63)$ & $-0.036(0.75)$ \\
\hline \multicolumn{4}{|l|}{$\mathrm{FEV}_{1} / \mathrm{FVC}^{2}$} \\
\hline Baseline $(n=68)$ & $0.0036(0.98)$ & $0.089(0.48)$ & $0.30(0.011)$ \\
\hline Six-year change $(n=65)$ & $0.044(0.69)$ & $0.15(0.21)$ & $-0.082(0.47)$ \\
\hline \multicolumn{4}{|l|}{ LAA $\%^{3}$} \\
\hline Baseline $(n=67)$ & $-0.14(0.24)$ & $-0.16(0.32)$ & $-0.28(0.058)$ \\
\hline Six-year change $(n=67)$ & $-0.13(0.23)$ & $-0.25(<0.01)$ & $-0.12(0.27)$ \\
\hline
\end{tabular}

Values are presented as standardized $\beta$ ( $p$ value). All 6-year change analyses were adjusted for the baseline outcome variable. Italicized data reached statistical significance for $p<0.05$. ISWD, incremental shuttle walk distance; LAA\%, low-attenuation area percentage; $\mathrm{FEV}_{1}$, forced expiratory volume in $1 \mathrm{~s}$; FVC, forced vital capacity; BMI, body mass index. ${ }^{1}$ Adjusted for baseline $\mathrm{FEV}_{1}$, gender, age, and height. ${ }^{2}$ Adjusted for baseline gender, age, pack-years, and active smoking status. ${ }^{3}$ Adjusted for baseline gender, age, and pack-years.

Serum Inflammatory Marker Associations with Fat Measures and Clinical Outcomes

Mediastinal fat and BMI were directly associated with circulating IL-6 levels $(p<0.01$; Table 3$)$. BMI also was directly associated with CRP levels $(p=0.033)$. Neither IL-6 nor CRP levels were significantly associated with cross-sectional or longitudinal change in walk distance, lung function, or LAA\%. Path analysis assessing 6-year change in LAA\% demonstrated that BMI had both a significant direct negative effect and a significant indirect positive effect on LAA\% change, which was mediated by CRP (RMSEA $=0.121,90 \%$ CI $=0-0.371$; Fig. 2). Path analysis further demonstrated a significant indirect negative relationship between BMI and ISWD mediated by CRP (RMSEA $=0.047,90 \% \mathrm{CI}=0-0.025$ : Fig. 3 ).

\section{Discussion}

In a cohort of current and former smokers, baseline subcutaneous chest fat was significantly associated with less emphysema progression over 6 years, while mediastinal fat was significantly associated with decreased ISWD and increased circulating IL-6 levels. The relationship between subcutaneous fat and emphysema progression as well as mediastinal fat and walk distance indicates a complex relationship between fat type, clinical outcome measures, and overall disease trajectory. Our findings suggest
Table 3. Baseline fat measure and natural log-transformed inflammatory marker associations

\begin{tabular}{llc}
\hline & IL-6 $(n=67)$ & CRP $(n=61)$ \\
\hline Mediastinal fat & $0.40(<0.01)$ & $0.13(0.32)$ \\
Subcutaneous fat & $0.10(0.33)$ & $0.048(0.76)$ \\
BMI & $0.49(<0.01)$ & $0.31(0.033)$ \\
\hline
\end{tabular}

Values are presented as standardized $\beta$ ( $p$ value). All analyses were adjusted for age and current smoking status. Italicized data reached statistical significance for $p<0.05$. IL-6, interleukin 6; CRP, C-reactive protein; BMI, body mass index.

that a more granular phenotyping approach with special attention to fat location may yield greater insight into mechanisms when studying the impact of obesity on individuals with obstructive lung disease.

The inverse association of subcutaneous fat with longitudinal change in quantitative emphysema in our cohort provides, to our knowledge, the first evidence of a relationship between a body composition measure and emphysema progression in smokers. Quantified emphysema and fat type have been studied infrequently. One cross-sectional study showed that abdominal subcutaneous fat on CT scan was inversely associated with LAA\% while abdominal visceral fat was not [24]. We did not find a similar cross-sectional association between chest 


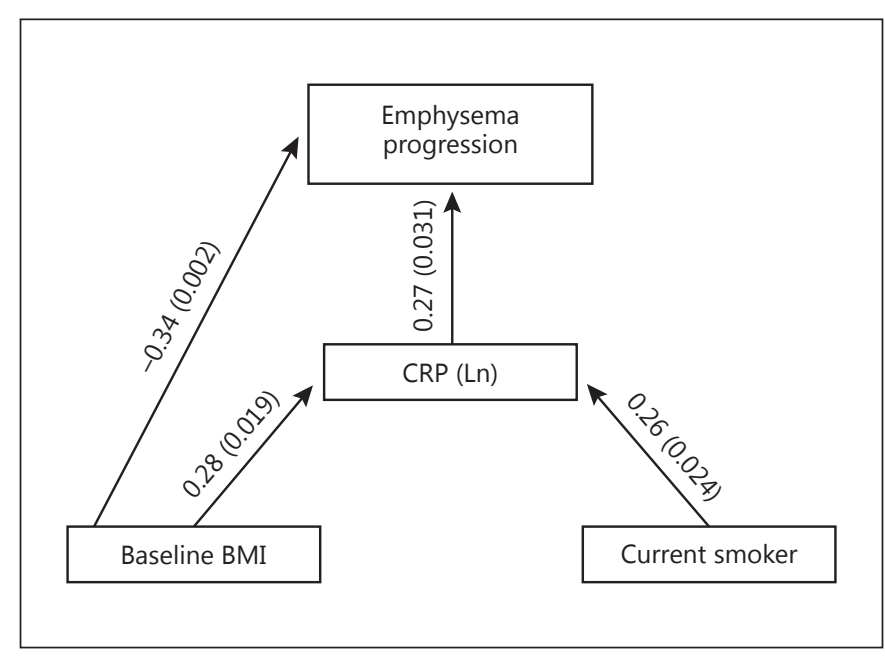

Fig. 2. Path analysis for 6-year LAA\% change (emphysema progression) showing two differing effects by BMI. Comparative fit index $(\mathrm{CFI})=0.93$, root mean square error of approximation $($ RMSEA $)=0.121(90 \% \mathrm{CI}=0-0.371)$. BMI, body mass index; CRP $(\mathrm{Ln})$, natural log-transformed C-reactive protein.

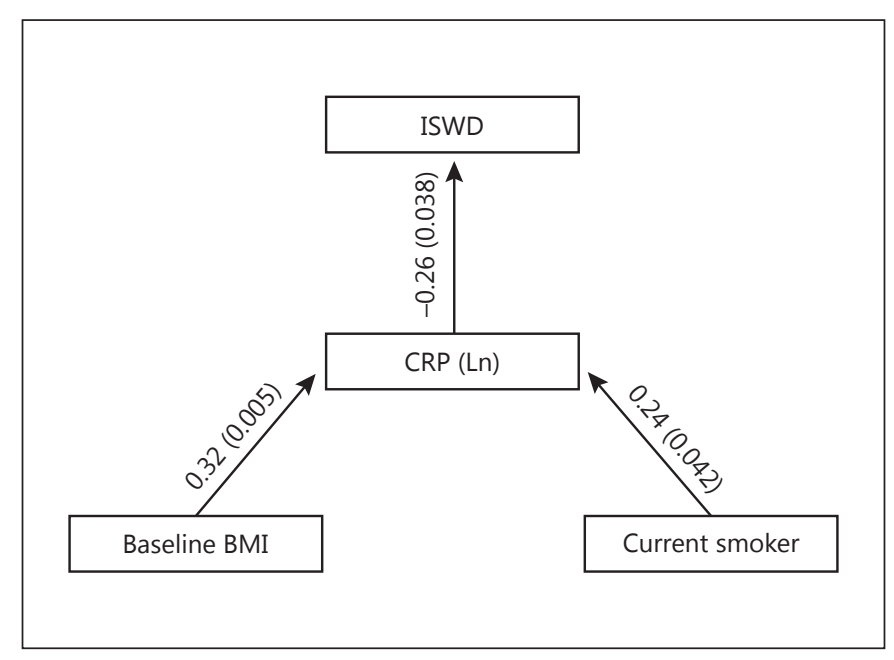

Fig. 3. Path analysis for ISWD showing BMI effect mediated by CRP. Comparative fit index $(\mathrm{CFI})=0.97$, root mean square error of approximation (RMSEA) $=0.047(90 \% \mathrm{CI}=0-0.025)$. BMI, body mass index; CRP (Ln), natural log-transformed C-reactive protein; ISWD, incremental shuttle walk distance.

subcutaneous fat and LAA\%, possibly due to inadequate power to detect this association given our sample size, differences in disease severity between cohorts, or regional differences in the technique used to assess subcutaneous fat in each study. Despite this, our study supports an inverse relationship between subcutaneous fat and change in emphysema over time in a cohort with relatively low disease burden that could reasonably be expected to be more pronounced in a population with more advanced disease.

The associations between fat location and clinical outcomes shown in our study have important implications for COPD phenotyping. Studies focusing on factor analysis to identify disease clusters have relied predominantly upon BMI to represent obesity in their modeling with variable results. In some studies, a higher BMI was associated with a cluster that had higher mortality and inflammation [25] as well as overall comorbidity burden [26]. Yet, another study using gene interaction networks to define COPD clusters based on inflammation-influenced genetic profiles showed no significant difference in BMI across groups [27]. Our path analysis also shows conflicting data with BMI having both a negative and an indirect positive relationship with emphysema progression. Our study suggests that the inclusion of fat location in addition to BMI as a cluster variable has the potential to add a new biometric dimension for more precise classification of COPD phenotypes and may explain these distinct but disparate clusters.

Our association of baseline mediastinal, but not subcutaneous, fat with decreased ISWD adds additional data to the growing body of evidence that mechanisms beyond the mechanical factors of obesity contribute to functional limitations in COPD [28]. Multiple studies have demonstrated that body composition measures such as BMI, total fat mass, and fat-free mass index are important determinants of exercise capacity in COPD patients [29-31]. Our study agrees with these previous studies and adds additional granularity by demonstrating that mediastinal fat may be playing a significant role, similar to a previous study, which found that visceral fat was independently associated with decreased exercise capacity in subjects with COPD [32]. While our biomarker data are limited by sample size, we found that circulating IL- 6 levels were strongly associated with mediastinal and not subcutaneous fat, suggesting that differential inflammatory patterns associated with fat type and location may contribute to the underlying mechanisms linking obesity to functional limitations in COPD. We were not able to find a significant link between circulating IL- 6 and walk distance in our study, despite path analysis showing that a relationship exists for BMI, likely due to the heterogeneous nature of both systemic inflammation and factors contributing to exercise capacity in COPD which has been previously shown to not directly correlate with inflammatory biomarkers [33]. 
While not assessed in our cohort, the relationship between COPD and adipokines has been studied by others in an effort to identify mechanisms linking adiposity and COPD outcomes. Adiponectin possesses predominantly anti-inflammatory properties [34], yet it was directly associated with worsening radiographic progression of emphysema in a large cross-sectional cohort [35], possibly as a counter-inflammatory molecule. Several longitudinal cohorts have demonstrated an inverse relationship between radiographic emphysema progression and the leptin to adiponectin ratio [36, 37], while a meta-analysis showed that leptin levels were elevated during exacerbations but not in stable COPD patients compared to healthy controls [38]. Body composition was approximated by BMI in these studies, and the addition of fat location, as in our study, may further clarify the relationship between adiponectin, leptin, radiographic emphysema, and COPD outcomes.

Our study has several strengths. The availability of a well-characterized cohort of participants with longitudinal demographic, clinical, and radiographic data enabled the investigation of novel and clinically relevant relationships that have been studied in such detail infrequently. Furthermore, patients with relatively mild disease are the desired target population in which to study progression given the greater opportunity for early, meaningful intervention for this irreversible disease. We also utilized manual CT scan processing, which is considered the standard to which various automated systems are compared and critiqued in the rapidly expanding field of CT characterization of fat [39-42]. Our quantification of mediastinal and subcutaneous fat allowed us to assess for differential associations with relevant COPD outcomes both at baseline and longitudinally, which, to our knowledge, is the first study of its kind. Finally, with chest CT imaging becoming more prevalent in smokers with the widespread institution of lung cancer screening programs, our use of chest CT imaging alone to quantify fat by location for COPD phenotyping is particularly relevant and has been shown to be a valid approximation of visceral fat for research purposes in a previous study [43].

Our study has several limitations that warrant further investigation. The minimal progression of airflow obstruction in our cohort over the 6-year study period likely decreased our ability to detect significant changes in spirometry and walk distance. A longer study period would likely capture more advanced progression and better characterize the associations we have detected in this sample. While our data contribute to the better characterization of at-risk smokers and early COPD patients, clinical phenotyping studies have traditionally focused on patients with more advanced disease and apparent comorbidities compared to our present study. However, cohort participants with the highest circulating biomarker levels were likewise at the extremes of disease severity, suggesting that our data may be more strongly supported in a cohort with more advanced disease. While this accurately represents how most clinical scans are done, it is difficult to determine if truncation of the subcutaneous fat biased the data. Finally, our results are from a single cohort and may or may not generalize to other cohorts, particularly those with more severe lung disease.

In summary, we have demonstrated that fat location on chest CT scan is differentially associated with emphysema progression, walk distance, $\mathrm{FEV}_{1} / \mathrm{FVC}$, and circulating biomarkers in smokers. With further validation of fat type association with emphysema in a larger cohort with more advanced disease, our data could help expand on existing COPD phenotype definitions and enable clinicians to utilize CT data obtained for other purposes to better characterize their patients with COPD. Ongoing validation and improvement of existing fat location automation algorithms will greatly enhance data collection in this research area and could eventually be used routinely as another prognostic biometric data point in the assessment and classification of patients with COPD.

\section{Funding Sources}

Sources of support: K23 HL095909-01, P50 HL084948, P50 CA90440, and P30 AG024827. This work was also funded by a grant from the Snee Reinhardt Charitable Foundation.

\section{Author Contributions}

J.G. and J.B.: conception, design, data acquisition, analysis, and writing. J.K.L.: design, data acquisition, and critical revision of the manuscript for important intellectual content. S.M.N.: analysis and critical revision of the manuscript for important intellectual content. J.P., D.C., Y.Z., and F.C.S.: critical revision of the manuscript for important intellectual content. 


\section{References}

1 Mannino DM, Kiriz VA: Changing the burden of COPD mortality. Int J Chron Obstruct Pulmon Dis 2006;1:219-233.

2 Landbo C, Prescott E, Lange P, Vestbo J, Almdal TP: Prognostic value of nutritional status in chronic obstructive pulmonary disease. Am J Respir Crit Care Med 1999;160:18561861.

3 Franssen FM, O'Donnell DE, Goossens GH, Blaak EE, Schols AM: Obesity and the lung: 5. Obesity and COPD. Thorax 2008;63:11101117.

4 Gu S, Li R, Leader JK, Zheng B, Bon J, Gur D, Sciurba F, Jin C, Pu J: Obesity and extent of emphysema depicted at CT. Clin Radiol 2015; 70:e14-e19.

5 Hanson C, Rutten EP, Wouters EF, Rennard S: Influence of diet and obesity on COPD development and outcomes. Int J Chron $\mathrm{Ob}$ struct Pulmon Dis 2014;9:723-733.

6 Marques MD, Santos RD, Parga JR, RochaFilho JA, Quaglia LA, Miname MH, Avila LF: Relation between visceral fat and coronary artery disease evaluated by multidetector computed tomography. Atherosclerosis 2010;209: 481-486.

7 van der Poorten D, Milner KL, Hui J, Hodge A, Trenell MI, Kench JG, London R, Peduto T, Chisholm DJ, George J: Visceral fat: a key mediator of steatohepatitis in metabolic liver disease. Hepatology 2008;48:449-457.

8 Mirza MS: Obesity, visceral fat, and NAFLD: querying the Role of adipokines in the progression of nonalcoholic fatty liver disease. ISRN Gastroenterol 2011;2011:592404.

9 Gilsanz V, Chalfant J, Mo AO, Lee DC, Dorey FJ, Mittelman SD: Reciprocal relations of subcutaneous and visceral fat to bone structure and strength. J Clin Endocrinol Metab 2009; 94:3387-3393.

10 Bredella MA, Ghomi RH, Thomas BJ, Torriani M, Brick DJ, Gerweck AV, Misra M, Klibanski A, Miller KK: Comparison of DXA and CT in the assessment of body composition in premenopausal women with obesity and anorexia nervosa. Obesity (Silver Spring) 2010;18:2227-2233.

11 Dey D, Nakazato R, Li D, Berman DS: Epicardial and thoracic fat - noninvasive measurement and clinical implications. Cardiovasc Diagn Ther 2012;2:85-93.

12 Bon J, Fuhrman CR, Weissfeld JL, Duncan SR, Branch RA, Chang CC, Zhang Y, Leader JK, Gur D, Greenspan SL, Sciurba FC: Radiographic emphysema predicts low bone mineral density in a tobacco-exposed cohort. Am J Respir Crit Care Med 2011;183:885-890.

13 Wilson DO, Weissfeld JL, Balkan A, Schragin JG, Fuhrman CR, Fisher SN, Wilson J, Leader JK, Siegfried JM, Shapiro SD, Sciurba FC: Association of radiographic emphysema and airflow obstruction with lung cancer. Am J Respir Crit Care Med 2008;178:738-744.
14 Müller NL SC, Miller RR, Abboud RT: “Density mask". An objective method to quantitate emphysema using computed tomography. Chest 1988;94:782-787.

15 Yoshizumi T NT, Yamane M, Islam AH, Menju M, Yamasaki K, Arai T, Kotani K, Funahashi T, Yamashita S, Matsuzawa Y: Abdominal fat: standardized technique for measurement at CT. Radiology 1999;211:283-286.

16 Rosito GA, Massaro JM, Hoffmann U, Ruberg FL, Mahabadi AA, Vasan RS, O’Donnell CJ, Fox CS: Pericardial fat, visceral abdominal fat, cardiovascular disease risk factors, and vascular calcification in a community-based sample: the Framingham Heart Study. Circulation 2008;117:605-613.

17 Walker JT, Maddan S: Understanding Statistics for the Social Sciences, Criminal Justice, and Criminology. Burlington, Burlington Jones and Bartlett Publishers, 2013.

18 Belousova EG HM, Xuan W, Peat JK: Factors that affect normal lung function in white Australian adults. Chest 1997;112:1539-1546.

19 Pepera G, Cardoso F, Taylor MJ, Peristeropoulos A, Sandercock GR: Predictors of shuttle walking test performance in patients with cardiovascular disease. Physiotherapy 2013; 99:317-322.

20 van den Borst B, Gosker HR, Koster A, Yu B, Kritchevsky SB, Liu Y, Meibohm B, Rice TB, Shlipak M, Yende S, Harris TB, Schols AM; Health, Aging, and Body Composition (Health ABC) Study: The influence of abdominal visceral fat on inflammatory pathways and mortality risk in obstructive lung disease. Am J Clin Nutr 2012;96:516-526.

21 Barnett AG, van der Pols JC, Dobson AJ: Regression to the mean: what it is and how to deal with it. Int J Epidemiol 2005;34:215-220.

22 Aldaham S, Foote JA, Chow HH, Hakim IA: Smoking status effect on inflammatory markers in a randomized trial of current and former heavy smokers. Int J Inflam 2015;2015: 439396.

23 Marsh HW, Morin AJ, Parker PD, Kaur G: Exploratory structural equation modeling: an integration of the best features of exploratory and confirmatory factor analysis. Ann Rev Clin Psychol 2014;10:85-110.

24 Furutate R, Ishii T, Wakabayashi R, Motegi T, Yamada K, Gemma A, Kida K: Excessive visceral fat accumulation in advanced chronic obstructive pulmonary disease. Int J Chron Obstruct Pulmon Dis 2011;6:423-430.

25 Rennard SI, Locantore N, Delafont B, TalSinger R, Silverman EK, Vestbo J, Miller BE, Bakke P, Celli B, Calverley PM, Coxson H, Crim C, Edwards LD, Lomas DA, MacNee W, Wouters EF, Yates JC, Coca I, Agusti A; Evaluation of COPD Longitudinally to Identify Predictive Surrogate Endpoints: Identification of five chronic obstructive pulmonary disease subgroups with different prognoses in the ECLIPSE cohort using cluster analysis. Ann Am Thorac Soc 2015;12:303-312.
26 Vanfleteren LE, Spruit MA, Groenen M, Gaffron S, van Empel VP, Bruijnzeel PL, Rutten EP, Op 't Roodt J, Wouters EF, Franssen FM: Clusters of comorbidities based on validated objective measurements and systemic inflammation in patients with chronic obstructive pulmonary disease. Am J Respir Crit Care Med 2013;187:728-735.

27 Chang Y, Glass K, Liu YY, Silverman EK, Crapo JD, Tal-Singer R, Bowler R, Dy J, Cho M, Castaldi P: COPD subtypes identified by network-based clustering of blood gene expression. Genomics 2016;107:51-58.

28 Laveneziana P, Palange P; ERS Research Seminar Faculty: Physical activity, nutritional status and systemic inflammation in COPD. Eur Respir J 2012;40:522-529.

29 Ischaki E, Papatheodorou G, Gaki E, Papa I, Koulouris N, Loukides S: Body mass and fatfree mass indices in COPD: relation with variables expressing disease severity. Chest 2007; 132:164-169.

30 Katz P, Iribarren C, Sanchez G, Blanc PD: Obesity and functioning among individuals with chronic obstructive pulmonary disease (COPD). COPD 2016;13:352-359.

31 Spruit MA, Watkins ML, Edwards LD, Vestbo J, Calverley PM, Pinto-Plata V, Celli BR, TalSinger R, Wouters EF; Evaluation of COPD Longitudinally to Identify Predictive Surrogate Endpoints (ECLIPSE) study investigators: Determinants of poor 6-min walking distance in patients with COPD: the ECLIPSE cohort. Respir Med 2010;104:849-857.

32 Eisner MD, Blanc PD, Sidney S, Yelin EH, Lathon PV, Katz PP, Tolstykh I, Ackerson L, Iribarren C: Body composition and functional limitation in COPD. Respir Res 2007;8:7.

33 Garrod R, Marshall J, Barley E, Fredericks S, Hagan G: The relationship between inflammatory markers and disability in chronic obstructive pulmonary disease (COPD). Prim Care Respir J 2007;16:236-240.

34 Shehzad A, Iqbal W, Shehzad O, Lee YS: Adiponectin: regulation of its production and its role in human diseases. Hormones 2012;11: 8-20.

35 Carolan BJ, Kim YI, Williams AA, Kechris K, Lutz S, Reisdorph N, Bowler RP: The association of adiponectin with computed tomography phenotypes in chronic obstructive pulmonary disease. Am J Respir Crit Care Med 2013;188:561-566.

36 Suzuki M, Makita H, Ostling J, Thomsen LH, Konno S, Nagai K, Shimizu K, Pedersen JH, Ashraf H, Bruijnzeel PL, Maciewicz RA, Nishimura M; Hokkaido COPD Cohort Study, Danish Lung Cancer Screening Trial Investigators: Lower leptin/adiponectin ratio and risk of rapid lung function decline in chronic obstructive pulmonary disease. Ann Am Thorac Soc 2014;11:1511-1519. 
37 Oh YM, Jeong BH, Woo SY, Kim SY, Kim H, Lee JH, Lim SY, Rhee CK, Yoo KH, Lee JH, Yoon HK, Sin DD, Lee SD, Kim EK, Park HY; KOLD Study Group: Association of plasma adipokines with chronic obstructive pulmonary disease severity and progression. Ann Am Thorac Soc 2015;12:1005-1012.

38 Zhou L, Yuan C, Zhang J, Yu R, Huang M, Adcock IM, Yao X: Circulating leptin concentrations in patients with chronic obstructive pulmonary disease: a systematic review and meta-analysis. Respiration 2013;86:512-522.

39 Dey D, Wong ND, Tamarappoo B, Nakazato R, Gransar H, Cheng VY, Ramesh A, Kakadiaris I, Germano G, Slomka PJ, Berman DS: Computer-aided non-contrast CT-based quantification of pericardial and thoracic fat and their associations with coronary calcium and metabolic syndrome. Atherosclerosis 2010;209:136-141.
40 Kim YJ, Lee SH, Kim TY, Park JY, Choi SH, Kim KG: Body fat assessment method using CT images with separation mask algorithm. J Digit Imaging 2013;26:155-162.

41 Kim YJ, Park JW, Kim JW, Park CS, Gonzalez JP, Lee SH, Kim KG, Oh JH: Computerized automated quantification of subcutaneous and visceral adipose tissue from computed tomography scans: development and validation study. JMIR Med Inform 2016;4:e2.

42 Zhao B, Colville J, Kalaigian J, Curran S, Jiang L, Kijewski P, Schwartz LH: Automated quantification of body fat distribution on volumetric computed tomography. J Comput Assist Tomogr 2006;30:777-783.
43 Ogawa E, Nakano Y, Ohara T, Muro S, Hirai T, Sato S, Sakai H, Tsukino M, Kinose D, Nishioka M, Niimi A, Chin K, Pare PD, Mishima M: Body mass index in male patients with COPD: correlation with low attenuation areas on CT. Thorax 2009;64:20-25.

44 Pauwels RA, Buist AS, Calverley PM, Jenkins CR, Hurd SS; GOLD Scientific Committee: Global strategy for the diagnosis, management, and prevention of chronic obstructive pulmonary disease. NHLBI/WHO Global Initiative for Chronic Obstructive Lung Disease (GOLD) Workshop summary. Am J Respir Crit Care Med 2001;163:12561276 . 